Cahiers $d u$ MONDE RUSSE

\section{Cahiers du monde russe}

Russie - Empire russe - Union soviétique et États indépendants

$55 / 3-4 \mid 2014$

Varia

\title{
Alistair Renfrew, Galin Tihanov, éds., Critical Theory in Russia and the West
}

Karine Zbinden

\section{OpenEdition}

\section{Journals}

Édition électronique

URL : http://journals.openedition.org/monderusse/8146

DOI : 10.4000/monderusse.8146

ISSN : $1777-5388$

\section{Éditeur}

Éditions de l'EHESS

\section{Édition imprimée}

Date de publication : 1 juillet 2014

Pagination : $521-523$

ISBN : 978-2-7132-2441-6

ISSN : $1252-6576$

\section{Référence électronique}

Karine Zbinden, «Alistair Renfrew, Galin Tihanov, éds., Critical Theory in Russia and the West », Cahiers du monde russe [En ligne], 55/3-4 | 2014, mis en ligne le 14 avril 2015, Consulté le 25 septembre 2020. URL : http://journals.openedition.org/monderusse/8146; DOI : https://doi.org/10.4000/monderusse. 8146

Ce document a été généré automatiquement le 25 septembre 2020.

(c) École des hautes études en sciences sociales 


\title{
Alistair Renfrew, Galin Tihanov, éds., Critical Theory in Russia and the West
}

\author{
Karine Zbinden
}

\section{RÉFÉRENCE}

Alistair RENFREW, Galin TIHANOV, éds., Critical Theory in Russia and the West, London

- New York : Routledge, 2010.

Critical Theory in Russia and the West est un ajout récent au catalogue de publications de la collection fondée en 2002 et caractérisée par une approche interdisciplinaire de la Russie et de l'Europe de l'Est, principalement communiste et postcommuniste, et dirigée par l'Association britannique des études slaves et est-européenne (BASEES). Cet ouvrage collectif s'inscrit donc parfaitement dans la lignée éditoriale de la série puisqu'il aborde le développement de la «théorie critique » (critical theory en anglais) depuis le berceau formaliste de la définition des études littéraires comme discipline à part entière jusqu'à son déclin au tournant du millénaire. Spécialistes des études slaves, principalement au sein des sciences humaines et comparatistes, mais également tout expert en études littéraires et théorie littéraire, voire philosophie du langage, y trouveront de quoi assouvir leur curiosité ainsi que de nouveaux horizons de recherche à explorer.

2 Le volume se donne pour mission de contester la notion selon laquelle la pensée théorique occidentale des années soixante et soixante-dix est l'héritière directe des travaux formalistes des années vingt en Union soviétique. Dans la préface, les directeurs de Critical Theory in Russia and the West se réclament d'une approche historicisante et contextualisatrice qui appréhende la pensée critique en tant que processus dynamique et «non comme l'utilisation d'un appareil fixe de techniques épistémologiques » ( $\mathrm{p}$.xvii). Autrement dit, ils se placent en porte-à-faux avec les 
développements théoriques desdites années soixante-soixante-dix (du moins selon l'optique de ses détracteurs à la suite de l'exportation de la "French theory » dans les années quatre-vingt dans le monde académique anglo-américain).

Dans «La Résurrection d'une poétique», Alastair Renfrew constate la nécessité d'abandonner la notion de continuité (l'on pourrait dire de filiation) entre les travaux formalistes et la théorie telle qu'elle s'est développée en Occident à partir des années soixante. Il affirme le besoin de considérer les différents mouvements théoriques du vingtième siècle par le biais des notions de «lutte» (struggle) et de «dialogue ». L'on peut regretter qu'à l'exception de Renfrew, la vaste majorité des contributions d'éminents spécialistes des études slaves, dont Svetlana Boym, Caryl Emerson, Mikhail Epstein, Alexander Etkind, Michael Holquist, Vitalii Makhlin, Inessa Medzhibovskaya et Thomas Seifrid entre autres, ne fassent que des références en passant à ladite pensée occidentale que l'ouvrage dans son ensemble prend à partie, avec les notables exceptions du chapitre de Carol Adlam, sur le féminisme postsoviétique et sa remise en question des liens de filiation entre l'Occident et la Russie cette fois et de celui d'Etkind consacré au roman russe comme locus de "colonisation interne», spécifique de l'Empire russe qui assujettit les siens propres et non l'Autre.

La notion de lutte est particulièrement adéquate dans le chapitre de Tihanov qui concerne les travaux de Gustav Špet qui se concentre sur la littérature et l'esthétique, comme son contemporain Mihail Bahtin, mais qui contrairement à ce dernier, n'est guère connu en Occident. Dès les années vingt, Špet se démarquera des mouvements dominants de l'époque, le sociologisme, le formalisme et la psychanalyse pour se tourner vers la philosophie, reprenant de Wilhelm von Humboldt la notion de « forme intérieure " et tentant de synthétiser la phénoménologie et l'herméneutique (p. 53). Cela lui vaudra, à partir des années trente, une mise à l'écart grandissante et une relégation à une existence de moins en moins productive intellectuellement jusqu'à son exécution en 1937.

Le concept de dialogue structure des contributions aussi variées que celle d'Emerson et de Medzhibovskaya sur Dostoevskij, Tolstoj et Bahtin, celle de Boym sur Viktor Šklovskij et Hannah Arendt et, dans un ordre différent, celle de Seifrid sur la " métaphore organiciste dans les théories du langage russes (et autres) ». Mais le livre, outre son aspect fragmenté que le titre totalisant ne laisse guère présager, fait profit d'autres fils conducteurs unificateurs. Epstein et Makhlin se tournent tous deux vers Bahtin pour imaginer le futur des sciences humaines : le premier en développant un lexique technologique de néologismes à partir des notions bakhtiniennes de commencement et d'inachèvement pour imaginer l'« interlation » comme alternative de la traduction, en tant que variation multilingue sur un même thème (p.180). Le second retombe sur la philosophie pour s'interroger sur la nature de ce qui vient "après et au-delà du texte ", déclarant que notre présent en sciences humaines se définit par le chaos plutôt que par la notion de crise, étant parvenus comme nous le sommes à la " fin de la conversation ", soit à un état d'individualisation généralisé à toutes les sphères culturelles (p. 196). Outre la personnalité dominante de Bahtin qui traverse nombre de chapitres, Šklovskij est une figure d'importance, ainsi que sa notion de "défamiliarisation" (ostranenie) qui permet de le rapprocher d'Arendt et des concepts de Fremdheit [caractère étranger] et Absonderlichkeit [particularité] (p.111) puis de la désidéologisation de la vie soviétique et postsoviétique par le biais de l'éloignement de la politique (p. 116-17). 
$6 \quad$ Il transparaît de l'ensemble quelque peu disparate de réflexions que la disparition de la philologie laisse un vide qu'il reste à combler dans les sciences humaines. Et la crise (ou le chaos) dont nous sommes actuellement victimes semblerait provenir du fait que l'étude du langage et de la littérature souffre du manque d'une perspective unifiée, prônée par la philologie, telle que l'ont pratiquée Roman Jakobson (dont l'épitaphe dit "Russkij filolog", comme nous le rappelle Holquist (p. 81)), et Nikolaj Trubeckoj, malheureusement trop peu représenté dans ce volume, comme Yurij Lotman d'ailleurs, qui auraient permis de s'écarter des sentiers bien battus du structuralisme selon Jakobson et du dialogue selon Bahtin. L'ouvrage évoque un sentiment nostalgique pour un monde où les études de lettres étaient mieux considérées et le rapport au langage et à la poésie plus direct. On peut regretter d'autant plus que le rôle du même Jakobson dans la transmission de certaines thèses et textes formalistes à l'avant-garde théorique des années soixante ne soit pas évoqué.

7 Critical Theory in Russia and the West offre néanmoins des éclairages précieux sur différentes questions d'importance et sur des figures moins connues des études littéraires (philologiques) russes du siècle dernier. Au-delà de la mission ambitieuse de l'ouvrage, l'on peut célébrer la tentative de repositionnement de la pensée théorique occidentale par rapport à ses antécédents russes.

\section{AUTEURS}

\section{KARINE ZBINDEN}

Université de Sheffield, G.B. 